\title{
Transarterial radioembolization for hepatocellular carcinoma: a review
}

This article was published in the following Dove Press journal:

Journal of Hepatocellular Carcinoma

25 July 2016

Number of times this article has been viewed

\author{
Rodolfo Sacco' \\ Caterina Conte ${ }^{2}$ \\ Emanuele Tumino' \\ Giuseppe Parisi' \\ Sara Marceglia ${ }^{3}$ \\ Salvatore Metrangolo' \\ Roberto Eggenhoffner ${ }^{4}$ \\ Giampaolo Bresci' \\ Giuseppe Cabibbo ${ }^{5}$ \\ Luca Giacomelli ${ }^{4}$ \\ 'Department of Gastroenterology, \\ Cisanello Hospital, Pisa, \\ ${ }^{2}$ Endocrinology and Metabolic \\ Diseases, Policlinico A. Gemelli, \\ Università Cattolica del Sacro Cuore, \\ Rome, ${ }^{3}$ Department of Engineering \\ and Architecture, University of \\ Trieste, Trieste, ${ }^{4}$ Department of \\ Surgical Sciences and Integrated \\ Diagnostics, School of Medicine, \\ Genova University, Genoa, ${ }^{5}$ Section of \\ Gastroenterology, DIBIMIS, University \\ of Palermo, Palermo, Italy
}

Correspondence: Rodolfo Sacco

Department of Gastroenterology,

Cisanello Hospital, Via Paradisa 2, 56I24

Pisa, Italy

Tel +395099 74II

Fax +3950997412

Email r.sacco@ao-pisa.toscana.it

\begin{abstract}
Hepatocellular carcinoma (HCC) is the most common type of liver cancer and is the second cause of death due to malignancy in the world. The treatment of HCC is complex and includes potentially curative and palliative approaches. However, both curative and palliative treatments for HCC are often associated with a not-completely favorable safety/efficacy ratio. Therefore, other treatment options appear necessary in clinical practice. Transarterial radioembolization has shown a promising efficacy in terms of disease control and is associated with a good safety profile. This review discusses the use of transarterial radioembolization in HCC, with a focus on the clinical aspects of this therapeutic strategy.
\end{abstract}

Keywords: hepatocellular carcinoma, transarterial radioembolization

\section{Introduction}

Hepatocellular carcinoma (HCC) remains a frequent and highly lethal type of cancer., ${ }^{1,2}$ According to the most recent data, the global incidence of HCC is still increasing, although it varies throughout the world; in 2013, 818,000 global deaths were caused by liver cancer, 9\% more than that in 2010 (752,000 global deaths)., The treatment for HCC is difficult and requires a multidisciplinary approach, whereby specialists in gastroenterology, hepatology, radiology, oncology, surgery, and others need to bring their expertise to provide patients with the best and most updated therapies. ${ }^{5}$ Transplantation and surgical removal of liver tumors represent the first-line therapy for HCC. Unfortunately, only $20 \%-30 \%$ of patients with HCC are good candidates for resection due to either multifocal unresectable tumors or their underlying chronic liver disease. ${ }^{6}$ Tumor ablation (such as injection of alcohol, acetic acid, microwaves, laser, cryoablation, and the most commonly used radiofrequency) has become a frequently used and extremely effective nonsurgical treatment that provides excellent local tumor control and favorable survival benefit ${ }^{7}$; however, its use in larger tumors has been unsuccessful.

Transarterial chemoembolization (TACE) is the treatment of choice in larger and later staged tumors. TACE consists of intra-arterial infusion of a Lipiodol and a chemotherapeutic agent such as doxorubicin, followed by an injection of embolic material such as gelatin sponge particles or other agents. ${ }^{8}$ However, the association with some contraindications makes it difficult to draw any firm conclusion about the tolerability of this treatment approach. ${ }^{9}$ Therefore, other treatment options appear necessary in clinical practice.

Transarterial radioembolization (TARE) has shown a promising efficacy in terms of disease control and is associated with a good safety profile. This review discusses 
the use of TARE in HCC, with a focus on the clinical aspects of this therapeutic strategy.

\section{TARE: an overview of basic principles}

TARE consists of the selective intra-arterial administration of microspheres loaded with a radioactive compound such as yttrium-90 or Lipiodol labeled with iodine ${ }^{131}$ or rhenium ${ }^{188}$ by means of a percutaneous access. Of note, TARE does not exert any macro-embolic effect; therefore, all the effects of the treatment depend solely on the radiation carried by the microspheres. Overall, a bulk of evidence supports the use of this technique in the treatment of primary and metastatic HCC and cholangiocarcinoma. ${ }^{10-19}$

Two different types of microspheres are currently available: the glass-made TheraSphere ${ }^{\circledR}$ and the resin-made SirSpheres ${ }^{\circledR}$. Although they differ in a number of characteristics, including size and number of injected microspheres, current evidence shows the substantial clinical efficacy of the two approaches. ${ }^{10-13}$ However, TheraSphere ${ }^{\circledR}$ has a low embolic power, with higher activity for each microsphere $(2,500 \mathrm{~Bq}$ vs $50 \mathrm{~Bq}$ for Sir-Spheres $\left.{ }^{\circledR}\right)$. Therefore, TheraSpehere ${ }^{\circledR}$ is more suitable when the prevention of vascular stasis and reflux is crucial, while it may not be the ideal choice for the treatment of large lesions. On the other hand, Sir-Spheres ${ }^{\circledR}$ is characterized by a higher embolic power, thus making it suitable in cases of large lesions; however, slow injections and angiographic control are necessary with this approach.

From a technical point of view, radioembolization comprises several stages. ${ }^{20-23}$ The first stage is the identification, according to a multidisciplinary assessment, of potentially eligible patients. Then, a diagnostic angiography is performed in order to evaluate the vascular anatomy and establish the most appropriate site of access. At the same time, labeled macroaggregates of albumin (MAA) are injected; their diffusion is similar to that of radioembolization microspheres and therefore can be studied by means of single-photon emission computed tomography/computed tomography to predict the actual diffusion of TARE microspheres. Of note, this simulation of diffusion allows a prediction of response to TARE $^{11}$ and therefore plays a crucial role in the selection of patients and in the personalization of treatment. The amount of yttrium-90 administered is then specifically calculated for each patient in order to achieve the desired activity. ${ }^{12,23-25}$ The use of dual-tracer 99m Tc-MAA-99m Tc-SC fusion singlephoton emission computed tomography, an imaging tool that merges data on radioactivity distribution with physiologic liver mapping, further enhances tailoring of treatment. ${ }^{26}$
Finally, microspheres are injected by a catheter within four weeks since the first visit.

However, TARE is not without its complications. ${ }^{27-36}$ Adverse events can be either due to delivery of toxic effects to nontumor tissues or by problems during the placement and manipulation of the catheter. Reported complications include liver failure or radio-induced liver disease (incidence up to $4 \%$ ), biliary problems $(<10 \%)$, post-radioembolization syndrome $(20 \%-55 \%)$, gastrointestinal problems $(<5 \%)$, and radio-induced pneumonia $(<1 \%)$. An appropriate selection of patients may exclude those at higher risk of reporting TARE-associated adverse events. Moreover, medical treatment with proton pump inhibitors, steroids, analgesics, and anti-emetics can prevent the onset or reduce the severity of the abovementioned symptoms.

\section{TARE in HCC: current clinical evidence}

The European Society of Medical Oncology defined TARE as a promising and suitable therapeutic option either as a "bridging" treatment or as the main therapy for patients who present diffuse intrahepatic tumor spread. ${ }^{37}$ In addition, the National Comprehensive Cancer Network recommends TARE for patients with unresectable disease due to inadequate hepatic reserve, poor performance status, comorbidities, or specific location and extension of the tumor. ${ }^{38}$ The National Cancer Institute states that this approach may be considered in selected patients with liver-confined $\mathrm{HCC}$, who are not eligible for transplant or resection. ${ }^{39}$

However, given its relatively recent introduction in clinical practice and the paucity of randomized phase III trials, more evidence on the use of TARE needs to be collected for a full evaluation of its benefits and risks. The use of TARE in different clinical situations is discussed in the following sections.

\section{Early-stage HCC}

Liver transplant remains the elective approach for patients with early-stage (according to the Barcelona Clinic Liver Cancer [BCLC]-A classification) HCC. However, given the paucity of donors, patients often experience disease progression while on the waiting list, and therefore "bridging therapies" are often used to delay progression. TARE has been recently proposed in this setting, ${ }^{40}$ but to date specific evidence remains scant, and procedural costs are high.

\section{Intermediate-stage HCC}

Patients classified as having intermediate-stage (BCLC-B) HCC present very heterogeneous characteristics. ${ }^{41,42}$ The 
elective treatment is TACE, but its use is often not feasible due to several contraindications.

TARE may represent a suitable approach in this setting, thanks to its overall favorable safety profile. Although no head-to-head prospective study versus TACE is available, the use of TARE has been investigated in a number of retrospective studies. TARE is more expensive than TACE; however, this latter technique requires multiple procedures and is more often associated with adverse events, therefore increasing the overall expense.

In a study comparing 123 patients assigned to TARE and 122 receiving TACE, the former approach was associated with longer time to progression (13.3 months vs 8.4 months; $P=0.046$ ) and less incidence of complications; however, no difference in overall survival (OS) was reported. ${ }^{43}$ These findings are in line with those reported in other studies. ${ }^{44-46}$ In a recent study, TARE was also associated with a lower need of hospitalization, when compared with TACE. ${ }^{47}$ Moreover, TARE showed a similar efficacy - in terms of survival - as sorafenib, which is the only medical treatment currently available for $\mathrm{HCC}$ and is also effective in patients with BCLC-B disease. ${ }^{48}$

In selected subjects with intermediate-stage $\mathrm{HCC}$, tumor shrinkage is sometimes feasible in order to reduce disease burden and allow resectability or transplantation. ${ }^{49}$ In a retrospective study, TARE and TACE were compared in terms of percentage of tumor shrinkage, with TARE showing the better outcomes $(-58 \%$ vs $-31 \% ; P=0.023) .{ }^{50}$

We feel that the possibility of effective tumor downsizing in selected patients widens the opportunities for the use of TARE. In addition, this technique can be suitable for patients with large extent of disease and modest residual liver volume. In this subpopulation of BCLC-B patients, TARE can induce hypotrophy of the treated hepatic lobe, and therefore hypertrophy of the contralateral lobe thus allowing surgery. ${ }^{51,52}$

\section{Advanced-stage HCC}

Sorafenib represents the elective treatment for patients affected from advanced-stage (BCLC-C) disease. ${ }^{53-56}$ In this setting, TARE has been associated with an OS of 6-10 months, ${ }^{16,17}$ lower than the results reported with sorafenib in clinical practice suggesting that TARE may be used in the treatment of patients who do not respond or are contraindicated to sorafenib treatment. In a recent small Spanish observational study on patients with HCC and portal vein invasion, treatment with TARE may be associated with a more prolonged survival compared with sorafenib. ${ }^{57}$ However, other studies are necessary to better elucidate the potential alternative role of TARE in the treatment of BCLC-C HCC.
According to the preliminary results of the European randomized SORAMIC trial, TARE followed by sorafenib appears as well tolerated as sorafenib alone. ${ }^{58}$ In more detail, the number of total (196 vs 222) and grade $\geq 3$ (43 vs 47) adverse events was similar in combination treatment and control arms, respectively. Moreover, the spectrum of adverse events was similar in the two groups.

Selection of patients does play a role also in the use of TARE for BCLC-C HCC. It has been shown that patients with portal vein thrombosis involving segmental or lobar branches treated with TARE achieve an OS of up to 23.2 months. ${ }^{59,60}$ On the other hand, patients with portal vein thrombosis of the common portal trunk or with distant metastases achieve much poorer outcomes, with OS often shorter than 6 months. ${ }^{19,61}$

\section{Conclusion and perspectives}

According to available evidence, TARE represents a feasible and promising therapy for the treatment of all stages of HCC. However, given the relative paucity of evidence on the use of TARE in HCC, the conduction of clinical trials on this approach will be of utmost importance in the upcoming years.

To this end, the proper evaluation of clinical outcomes associated with TARE becomes crucial. At present, the efficacy of this technique is usually assessed by measuring changes in tumor markers or by radiological findings. ${ }^{62,63}$ However, tumor markers are often not specific and may fail in providing well-grounded clinical indications. ${ }^{64}$ The use of adequate evaluation criteria, such as the mRECIST criteria, can enhance accuracy. ${ }^{65,66}$ Of note, tumor necrosis determined by TARE is often irregular in distribution and contrast enhancement; therefore, the use of volumetric measurements of tumor necrosis has been proposed for the early identification of responders. ${ }^{67,68}$ These evaluation approaches will allow a more comprehensive evaluation of TARE pros and cons in the upcoming years.

\section{Acknowledgments}

Editorial assistance for the preparation of this manuscript was provided by Sara Parodi, $\mathrm{PhD}$; this assistance was supported by internal funds.

\section{Disclosure}

The authors report no conflicts of interest in this work.

\section{References}

1. El-Serag HB, Rudolph KL. Hepatocellular carcinoma: epidemiology and molecular carcinogenesis. Gastroenterology. 2007;132(7):2557-2576.

2. Ozenne V, Bouattour M, Goutté N, et al. Prospective evaluation of the management of hepatocellular carcinoma in the elderly. Dig Liver Dis. 2011;43(12):1001-1005. 
3. Lozano R, Naghavi M, Foreman K, et al. Global and regional mortality from 235 causes of death for 20 age groups in 1990 and 2010: a systematic analysis for the Global Burden of Disease Study 2010. Lancet. 2012;380(9859):2095-2128.

4. GBD 2013 Risk Factors Collaborators, Forouzanfar MH, Alexander L, et al. Global, regional, and national comparative risk assessment of 79 behavioural, environmental and occupational, and metabolic risks or clusters of risks in 188 countries, 1990-2013: a systematic analysis for the Global Burden of Disease Study 2013. Lancet. 2015;386(10010): 2287-2323.

5. Mazzanti R, Arena U, Tassi R. Hepatocellular carcinoma: where are we? World J Exp Med. 2016;6(1):21-36.

6. Bodzin AS, Busuttil RW. Hepatocellular carcinoma: advances in diagnosis, management, and long term outcome. World J Hepatol. 2015;7(9): $1157-1167$.

7. Kang TW, Rhim H. Recent advances in tumor ablation for hepatocellular carcinoma. Liver Cancer. 2015;4(3):176-187.

8. Woo HY, Heo J. Transarterial chemoembolization using drug eluting beads for the treatment of hepatocellular carcinoma: now and future. Clin Mol Hepatol. 2015;21(4):344-348.

9. Raoul JL, Sangro B, Forner A, et al. Evolving strategies for the management of intermediate-stage hepatocellular carcinoma: available evidence and expert opinion on the use of transarterial chemoembolization. Cancer Treat Rev. 2011;37(3):212-220.

10. Sangro B, Salem R, Kennedy A, Coldwell D, Wasan H. Radioembolization for hepatocellular carcinoma: a review of the evidence and treatment recommendations. Am J Clin Oncol. 2011;34(4):422-431.

11. Garin E, Lenoir L, Rolland Y, et al. Dosimetry based on $99 \mathrm{mTc}-$ macroaggregated albumin SPECT/CT accurately predicts tumor response and survival in hepatocellular carcinoma patients treated with 90Y-loaded glass microspheres: preliminary results. $J$ Nucl Med. 2012;53(2):255-263.

12. Chiesa C, Maccauro M, Romito R, et al. Need, feasibility and convenience of dosimetric treatment planning in liver selective internal radiation therapy with $(90) \mathrm{Y}$ microspheres: the experience of the National Tumor Institute of Milan. Q J Nucl Med Mol Imaging. 2011;55(2): 168-197.

13. Lau WY, Kennedy AS, Kim YH, et al. Patient selection and activity planning guide for selective internal radiotherapy with yttrium-90 resin microspheres. Int J Radiat Oncol Biol Phys. 2012;82(1):401-407.

14. Ariel IM, Pack GT. Treatment of inoperable cancer of the liver by intraarterial radioactive isotopes and chemotherapy. Cancer. 1967;20(5): 793-804.

15. Blanchard RJ, Grotenhuis I, Lafave JW, Frye CW, Perry JF. Treatment of experimental tumors; utilization of radioactive microspheres. Arch Surg. 1964;89:406-410.

16. Salem R, Lewandowski RJ, Mulcahy MF, et al. Radioembolization for hepatocellular carcinoma using yttrium-90 microspheres: a comprehensive report of long-term outcomes. Gastroenterology. 2010;138(1): 52-64.

17. Sangro B, Carpanese L, Cianni R, et al; European Network on Radioembolization with Yttrium-90 Resin Microspheres (ENRY). Survival after yttrium-90 resin microsphere radioembolization of hepatocellular carcinoma across Barcelona clinic liver cancer stages: a European evaluation. Hepatology. 2011;54(3):868-878.

18. Hilgard P, Hamami M, Fouly AE, et al. Radioembolization with yttrium-90 glass microspheres in hepatocellular carcinoma: European experience on safety and longterm survival. Hepatology. 2010;52(5): 1741-1749.

19. Kulik LM, Carr BI, Mulcahy MF, et al. Safety and efficacy of $90 \mathrm{Y}$ radiotherapy for hepatocellular carcinoma with and without portal vein thrombosis. Hepatology. 2008;47(1):71-81.

20. Bester L, Meteling B, Boshell D, Chua TC, Morris DL. Transarterial chemoembolisation and radioembolisation for the treatment of primary liver cancer and secondary liver cancer: a review of the literature. J Med Imaging Radiat Oncol. 2014;58(3):341-352.
21. Covey AM, Brody LA, Maluccio MA, Getrajdman GI, Brown KT. Variant hepatic arterial anatomy revisited: digital subtraction angiography performed in 600 patients. Radiology. 2002;224(2):542-547.

22. Ilhan H, Goritschan A, Paprottka P, et al. Systematic evaluation of tumoral 99mTc-MAA uptake using SPECT and SPECT/CT in 502 patients before 90Y radioembolization. $J$ Nucl Med. 2015;56(3):333-338.

23. Ho S, Lau WY, Leung TW, Chan M, Johnson PJ, Li AK. Clinical evaluation of the partition model for estimating radiation doses from yttrium-90 microspheres in the treatment of hepatic cancer. Eur J Nucl Med. 1997;24(3):293-298.

24. MDS Nordion. TheraSphere ${ }^{\circledR}$ Yttrium-90 Glass Microspheres US [package insert]. USA: MDS Nordion; 2007.

25. Sirtex Medical. IR-Spheres ${ }^{\circledR}$ Training Program: Physicians and Institutions. Lane Cove: Sirtex Medical.

26. Lam MG, Goris ML, Iagaru AH, Mittra ES, Louie JD, Sze DY. Prognostic utility of $90 \mathrm{Y}$ radioembolization dosimetry based on fusion 99mTc-macroaggregated albumin-99mTc-sulfur colloid SPECT. $J$ Nucl Med. 2013;54(12):2055-2061.

27. Jakobs TF, Saleem S, Atassi B, et al. Fibrosis, portal hypertension, and hepatic volume changes induced by intra-arterial radiotherapy with 90yttrium microspheres. Dig Dis Sci. 2008;53(9):2556-2563.

28. Sangro B, Gil-Alzugaray B, Rodriguez J, et al. Liver disease induced by radioembolization of liver tumors: description and possible risk factors. Cancer. 2008;112(7):1538-1546.

29. Atassi B, Bangash AK, Lewandowski RJ, et al. Biliary sequelae following radioembolization with yttrium-90 microspheres. JVasc Interv Radiol. 2008;19(5):691-697.

30. Kennedy AS, Coldwell D, Nutting C, et al. Resin 90Y-microsphere brachytherapy for unresectable colorectal liver metastases: modern USA experience. Int J Radiat Oncol Biol Phys. 2006;65(2):412-425.

31. Murthy R, Xiong H, Nunez R, et al. Yttrium 90 resin microspheres for the treatment of unresectable colorectal hepatic metastases after failure of multiple chemotherapy regimens: preliminary results. J Vasc Interv Radiol. 2005;16(7):937-945.

32. Murthy R, Brown DB, Salem R, et al. Gastrointestinal complications associated with hepatic arterial yttrium-90 microsphere therapy. JVasc Interv Radiol. 2007;18(4):553-561.

33. Szyszko T, Al-Nahhas A, Tait P, et al. Management and prevention of adverse effects related to treatment of liver tumours with $90 \mathrm{Y}$ microspheres. Nucl Med Commun. 2007;28(1):21-24.

34. Leung TW, Lau WY, Ho SK, et al. Radiation pneumonitis after selective internal radiation treatment with intraarterial 90yttrium-microspheres for inoperable hepatic tumors. Int J Radiat Oncol Biol Phys. 1995;33(4):919-924.

35. Salem R, Parikh P, Atassi B, et al. Incidence of radiation pneumonitis after hepatic intra-arterial radiotherapy with yttrium-90 microspheres assuming uniform lung distribution. Am J Clin Oncol. 2008;31(5):431-438.

36. Salem R, Thurston KG. Radioembolization with 90Yttrium microspheres: a state-of-the-art brachytherapy treatment for primary and secondary liver malignancies. Part 1: technical and methodologic considerations. J Vasc Interv Radiol. 2006;17(8):1251-1278.

37. Jelic S, Sotiropoulos GC; ESMO Guidelines Working Group. Hepatocellular carcinoma: ESMO clinical practice guidelines for diagnosis, treatment and follow-up. Ann Oncol. 2010;21(suppl 5):v59-v64.

38. National Comprehensive Cancer Network (NCCN) [webpage on the Internet]. National Comprehensive Cancer Network Clinical Practice Guidelines in Oncology. Hepatobiliary Guidelines. V2. 2010. Available from: http://www.nccn.org/professionals/physician_gls/PDF/hepatobiliary.pdf. Accessed December 30, 2015.

39. Thomas MB, Jaffe D, Choti MM, et al. Hepatocellular carcinoma: consensus recommendations of the National Cancer Institute Clinical Trials Planning Meeting. J Clin Oncol. 2010;28(25):3994-4005.

40. Kulik LM, Atassi B, van Holsbeeck L, et al. Yttrium-90 microspheres (TheraSphere) treatment of unresectable hepatocellular carcinoma: downstaging to resection, RFA and bridge to transplantation. J Surg Oncol. 2006;94(7):572-586. 
41. Lencioni R. Loco-regional treatment of hepatocellular carcinoma. Hepatology. 2010;52(2):762-773.

42. Piscaglia F, Bolondi L. The intermediate hepatocellular carcinoma stage: should treatment be expanded? Dig Liver Dis. 2010;42(suppl 3): S258-S263.

43. Salem R, Lewandowski RJ, Kulik L, et al. Radioembolization results in longer time-to-progression and reduced toxicity compared with chemoembolization in patients with hepatocellular carcinoma. Gastroenterology. 2011;140(2):497.e2-507.e2.

44. Kooby DA, Egnatashvili V, Srinivasan S, et al. Comparison of yttrium-90 radioembolization and transcatheter arterial chemoembolization for the treatment of unresectable hepatocellular carcinoma. J Vasc Interv Radiol. 2010;21(2):224-230.

45. Carr BI, Kondragunta V, Buch SC, Branch RA. Therapeutic equivalence in survival for hepatic arterial chemoembolization and yttrium 90 microsphere treatments in unresectable hepatocellular carcinoma: a two-cohort study. Cancer. 2010;116(5):1305-1314.

46. Moreno-Luna LE, Yang JD, Sanchez W, et al. Efficacy and safety of transarterial radioembolization versus chemoembolization in patients with hepatocellular carcinoma. Cardiovasc Intervent Radiol. 2013;36(3): 714-723.

47. El Fouly A, Ertle J, El Dorry A, et al. In intermediate stage hepatocellular carcinoma: radioembolization with yttrium 90 or chemoembolization? Liver Int. 2015;35(2):627-635.

48. Gramenzi A, Golfieri R, Mosconi C, et al; BLOG (Bologna Liver Oncology Group). Yttrium-90 radioembolization vs sorafenib for intermediate-locally advanced hepatocellular carcinoma: a cohort study with propensity score analysis. Liver Int. 2015;35(3):1036-1047.

49. Iñarrairaegui M, Pardo F, Bilbao JI, et al. Response to radioembolization with yttrium-90 resin microspheres may allow surgical treatment with curative intent and prolonged survival in previously unresectable hepatocellular carcinoma. Eur J Surg Oncol. 2012;38(7):594-601.

50. de la Torre M, Buades-Mateu J, de la Rosa PA, et al. A comparison of survival in patients with hepatocellular carcinoma and portal vein invasion treated by radioembolization or sorafenib. Liver Int. Epub $2016 \mathrm{Feb} 22$.

51. Lewandowski RJ, Kulik LM, Riaz A, et al. A comparative analysis of transarterial downstaging for hepatocellular carcinoma: chemoembolization versus radioembolization. Am J Transplant. 2009;9(8): 1920-1928.

52. Vouche M, Lewandowski RJ, Atassi R, et al. Radiation lobectomy: timedependent analysis of future liver remnant volume in unresectable liver cancer as a bridge to resection. J Hepatol. 2013;59(5):1029-1036.

53. Gaba RC, Lewandowski RJ, Kulik LM, et al. Radiation lobectomy: preliminary findings of hepatic volumetric response to lobar yttrium-90 radioembolization. Ann Surg Oncol. 2009;16(6):1587-1596.

54. Galle P, Blanc J, Van Laethem JL. Efficacy and safety of sorafenib in patients with advanced hepatocellular carcinoma and prior antitumor therapy: a subanalysis from the SHARP trial. $J$ Hepatol. 2008; 48:S372
55. Bruix J, Raoul JL, Sherman M, et al. Efficacy and safety of sorafenib in patients with hepatocellular carcinoma (HCC): subanalysis of Sharp trial based on Barcelona Clinic Liver Cancer (BCLC) stage. J Hepatol. 2009;50:S28-S29.

56. Cheng AL, Kang YK, Chen Z, et al. Efficacy and safety of sorafenib in patients in the Asia-Pacific region with advanced hepatocellular carcinoma: a phase III randomised, double-blind, placebo-controlled trial. Lancet Oncol. 2009;10(1):25-34.

57. Llovet JM, Ricci S, Mazzaferro V, et al. Sorafenib in advanced hepatocellular carcinoma. $N$ Engl J Med. 2008;359(4):378-390.

58. Ricke J, Bulla K, Kolligs F, et al. Safety and toxicity of radioembolization plus Sorafenib in advanced hepatocellular carcinoma: analysis of the European multicentre trial SORAMIC. Liver Int. 2015;35(2): $620-626$.

59. Mazzaferro V, Sposito C, Bhoori S, et al. Yttrium-90 radioembolization for intermediate-advanced hepatocellular carcinoma: a phase 2 study. Hepatology. 2013;57(5):1826-1837.

60. Garin E, Lenoir L, Edeline J, et al. Boosted selective internal radiation therapy with 90Y-loaded glass microspheres (B-SIRT) for hepatocellular carcinoma patients: a new personalized promising concept. Eur J Nucl Med Mol Imaging. 2013;40(7):1057-1068.

61. Woodall CE, Scoggins CR, Ellis SF, et al. Is selective internal radioembolization safe and effective for patients with inoperable hepatocellular carcinoma and venous thrombosis? J Am Coll Surg. 2009;208(3):375-382.

62. Atassi B, Bangash AK, Bahrani A, et al. Multimodality imaging following $90 \mathrm{Y}$ radioembolization: a comprehensive review and pictorial essay. Radiographics. 2008;28(1):81-99.

63. RiazA, Ryu RK, Kulik LM, et al. Alpha-fetoprotein response after locoregional therapy for hepatocellular carcinoma: oncologic marker of radiologic response, progression, and survival. J Clin Oncol. 2009;27(34): 5734-5742.

64. Chan SL, Mo FK, Johnson PJ, et al. New utility of an old marker: serial alpha-fetoprotein measurement in predicting radiologic response and survival of patients with hepatocellular carcinoma undergoing systemic chemotherapy. J Clin Oncol. 2009;27(3):446-452.

65. Lencioni R, Llovet JM. Modified RECIST (mRECIST) assessment for hepatocellular carcinoma. Semin Liver Dis. 2010;30(1):52-60.

66. Riaz A, Kulik L, Lewandowski RJ, et al. Radiologic-pathologic correlation of hepatocellular carcinoma treated with internal radiation using yttrium-90 microspheres. Hepatology. 2009;49(4):1185-1193.

67. Monsky WL, Garza AS, Kim I, et al. Treatment planning and volumetric response assessment for Yttrium-90 radioembolization: semiautomated determination of liver volume and volume of tumor necrosis in patients with hepatic malignancy. Cardiovasc Intervent Radiol. 2011;34(2):306-318.

68. Galizia MS, Töre HG, Chalian H, McCarthy R, Salem R, Yaghmai V. MDCT necrosis quantification in the assessment of hepatocellular carcinoma response to yttrium 90 radioembolization therapy: comparison of two-dimensional and volumetric techniques. Acad Radiol. 2012;19(1):48-54
Journal of Hepatocellular Carcinoma

\section{Publish your work in this journal}

The Journal of Hepatocellular Carcinoma is an international, peerreviewed, open access journal that offers a platform for the dissemination and study of clinical, translational and basic research findings in this rapidly developing field. Development in areas including, but not limited to, epidemiology, vaccination, hepatitis therapy, pathology and

\section{Dovepress}

molecular tumor classification and prognostication are all considered for publication. The manuscript management system is completely online and includes a very quick and fair peer-review system, which is all easy to use. Visit http://www.dovepress.com/testimonials.php to read real quotes from published authors. 